\title{
Assessment of the level of stakeholders' satisfaction with respect to the scope: A methodological proposal for mining projects
}

\author{
Evaluación del nivel de satisfacción de los grupos de interés respecto al alcance: Una propuesta \\ metodológica para proyectos mineros
}

\author{
Alfredo González León (Main and Corresponding Author) \\ Universidad Católica del Norte, Departamento Gestión de la Construcción \\ Ave. Angamos 0610, Antofagasta (Chile) \\ agonzale@ucn.cl
}

\section{Myriam Sánchez Pinto}

Universidad Católica del Norte, Departamento Gestión de la Construcción Ave. Angamos 0610, Antofagasta (Chile)

msanchezpinto@gmail.com

\section{Boris Heredia Rojas}

Universidad Católica del Norte, Departamento Gestión de la Construcción Ave. Angamos 0610, Antofagasta (Chile)

bheredia@ucn.cl

Manuscript Code: 1191

Date of Acceptance/Reception: 11.04.2019/16.10.2018

DOI: 10.7764/RDLC.18.1.186

\begin{abstract}
Traditionally, stakeholders have been underrepresented when defining the scope of a project, generating numerous problems during the execution and implementation of the project. Through this study, a procedure is proposed for helping the project management team to systematically identify and prioritize the involvement of each key stakeholder in mining projects. The procedure provides a tool to assess the level of completeness in defining the scope of the project, considering the stakeholders' needs. With this methodological proposal, decision-makers and project managers will be able to ensure that the requirements and concerns of the stakeholders are properly considered in the early stages of the project, allowing a better level of satisfaction with respect to the desired scope of the project.
\end{abstract}

Keywords: Stakeholder management, scope management, level of satisfaction, project life cycle.

\section{Resumen}

Tradicionalmente, los grupos de interés han sido poco representados al momento de la definición del alcance de un proyecto, generando numerosos problemas durante la ejecución y puesta en marcha del mismo. A través de este estudio, se propone un procedimiento que ayude al equipo de gestión del proyecto a identificar y priorizar sistemáticamente el involucramiento de cada grupo de interés clave en proyectos mineros. El procedimiento entrega una herramienta para evaluar el nivel de completitud en la definición de alcance del proyecto incorporando a los grupos de interés. Con esta propuesta metodológica los tomadores de decisión y gerentes de proyecto podrán asegurar que los requisitos y preocupaciones de los interesados son considerados apropiadamente en las etapas tempranas del proyecto, permitiendo un mejor nivel de satisfacción con respecto al alcance deseado del proyecto.

Palabras clave: Gestión de interesados, gestión del alcance, nivel de satisfacción, ciclo de vida del proyecto.

The issue of considering the interest groups (IG) and their influence on projects have been developed significantly since the work of Freeman (2010), so much so that today the management of IG corresponds to a formal area of the project management discipline. Researchers such as Walker, Bourne, \& Shelley (2008), Bryson (2004), Atkinson (2006), Smith \& Graetz (2006), and PMI (2017) have highlighted that the IG participation during the project's life cycle has an undeniable impact on project results. Regardless of the method of identification and classification, the project manager and his team must balance the needs and expectations of all relevant IGs, in order to ensure the successful delivery of the project (Bourne \& Walker, 2008). The main problem resides in IGs not getting involved early and systematically in projects, for example, during the engineering studies. Project managers are limited to reporting to IGs the scope of the project once the decisions have been made and which, in most cases, have a negative impact on them. 
Scope management issues in projects are especially relevant in countries that depend on the mining industry for their economic development. Hence, it is appropriate to address the issue of the IG management, in terms of their involvement in the early stages of the projects, and in the understanding that the satisfaction of their interests, concerns, and expectations is critical for obtaining successful projects and value added to mining-related businesses. However, in many mining operations, there is an open and unresolved conflict associated with the style, timing and method of how projects are managed in the pre-investment stage, and specifically how the IGs are involved in these projects. According to experience, this practice would explain a large part of the increases in costs and work delays in the project portfolio. Also, it explains the general dissatisfaction of IGs with the final results obtained with the execution of the projects in its investment stage.

In this sense, the current study highlights the importance of the key IGs' participation associated with a project in each scope definition element (usually in the early stages of the project), in order to improve the level of completeness of the project's scope definition. Based on the Project Management Body of Knowledge (PMBOK $\left.{ }^{\circledR}\right)(2017)$ and other project management approaches, the aim is, therefore, to establish a procedure to evaluate the completeness of the scope of mining projects, measuring the level of IGs' satisfaction during the pre-investment stage and allowing unnecessary changes across the design and execution phases.

In particular, the following objectives are proposed:

a) To identify the minimum elements of the scope that should be considered in the definition of projects in the preinvestment stage.

b) To identify the key IGs that should be involved in the definition of the scope components and to establish their contribution based on the $\mathrm{PMBOK}^{\circledR}$.

c) To propose a practical procedure to evaluate the degree of completeness of the definition of the project scope, measuring the degree of IG's satisfaction.

Applying the case method developed by Yin (2009), this study proposes a procedure for early assessment of completeness of the project scope. The suggested procedure is a tool so that project managers and their teams can evaluate the degree of scope definition of the project, considering different points of view, requirements and needs of the IG involved, and the levels of the relative importance of their contributions to complete the desired project scope.

State of the art

The purpose of this study is to develop a methodology for the systematic incorporation of the IGs and thus increasing their level of satisfaction with respect to the project scope. For achieving this goal, it is necessary to look for better ways to manage the IGs. Therefore, the term "satisfaction" and how to improve it is now investigated through a literature review.

Dawis (1994) claims that satisfaction is a feeling resulting from the individual evaluation of a situation; that is, the degree to which an individual perceives situations that meet their needs and desires. In this way, satisfaction can be described as a feeling of happiness or well-being, whereas dissatisfaction is a negative feeling often manifested as discomfort with a situation (Dawis, 1994). This definition is based on the theory of satisfaction of needs proposed by Maslow (1943), who establishes two fundamental premises: unmet needs motivate behaviors; and a specific need that is widely satisfied becomes less motivating of behaviors, while high levels of need become great motivators. He also identifies five levels of needs: psychological needs; security needs; social needs; esteem needs; and, needs for self-development. Regarding this description, when people meet the first two levels of needs, they will be motivated to meet unmet needs at the highest level. The three highest levels of human needs describe the drive for people to be part of something bigger than themselves, i.e., people will feel more social, esteemed and self-developed when they are involved in the environment, participating in shaping their lives, solving problems and making decisions (Maslow, 1943).

On the other hand, the importance of the management of each key interest group (IG) in projects is evident in the literature on strategic management and project management. In the last 20 years, a large group of researchers (Johnson \& Scholes, 1999; McElroy \& Mills, 2000; Mitchell, Agle, \& Wood, 1997) have proposed various theories, definitions, and conceptual frameworks to manage stakeholders effectively. For example, Mitchell et al. (1997) define a typology of IG according to their power, urgency, and legitimacy related to the distribution of their attributes, and they establish seven IG types: inactive, discretionary, demanding, dominant, dangerous, dependent and definitive. Johnson \& Scholes (1999) propose the IG map which identifies four categories according to the level of power and interest in the project: key player, keep informed, keep satisfied and minimum effort. Complementarily, McElroy \& Mills (2000) categorize the IGs on a scale of five levels with respect to the commitment they have towards the project: active opposition, passive 
opposition, no commitment, passive support, and active support. Contrary to the IG power and interest matrix suggested by Johnson \& Scholes (1999), Ward \& Chapman (2003) maintain four IG categories but, given the difficulty of measuring power and interest, they change the matrix to one of impact and probability. With an emphasis from the IG, Bourne \& Walker (2005) develop the interest intensity index of the project which varies from very low to very high, which relates the power that an individual IG has to exert influence. Going a step further, Olander (2007) establishes a methodology for the analysis of the IG impact in the management of projects combining the IG attributes (Mitchell et al., 1997), the level of commitment (McElroy \& Mills, 2000) and the interest intensity index (Bourne \& Walker, 2005). Finally, the Project Management Institute (PMI, 2017) includes stakeholders management in the body of knowledge of project management $\left(\mathrm{PMBOK}^{\circledR}\right)$ as a new area of knowledge with the focus not only on managing the expectations of IGs, but also in ensuring their participation in activities and key decisions for the success of the project.

In this way, the management of IG refers to the application of knowledge, skills, tools, and techniques to project activities in order to reach or exceed the needs and expectations of the stakeholders on a project (PMI, 2017). Chinyio and Akintoye (2008) recognize that IG studies have aimed to understand, analyze, describe and manage IG. Freeman (2010) shapes the concept of stakeholders management and stakeholders theory in an influential document that presents a fundamental shift in how business strategy is conceptualized. The basic premise of the IG theory is that a project has relationships with many individuals, groups, and organizations in its external environment. These individuals, groups, and organizations affect the decisions of the project (Bourne \& Walker, 2005). The IG theory tries to answer the essential question of which IG needs more attention and provides a solid basis to identify, classify and categorize IGs, and understand their behaviors to ensure effective management (Aaltonen, Jaakko, \& Tuomas, 2008). According to Phillips (2003), IG theory should also be concerned with who contributes to decision making and who benefits from the results of those decisions.

Participation and equity in the management of the IGs are crucial for project planning (Gallego-Ayala \& Juízo, 2014; Mostafa \& El-Gohary, 2014; Rosso, Bottero, Pomarico, La Ferlita, \& Comino, 2014). According to Chinyio and Akintoye (2008), the project industry needs an integrative approach to involve the associated IGs. The IG expectations must be respected and reflected in the project, and their involvement and participation must be managed according to their importance in the project (Chinyio \& Akintoye, 2008). There is a clear need to investigate the ideal involvement of IG for each individual specialty, and to investigate its impacts throughout the project's lifecycle. In particular, the impacts on the pre-investment project planning process deserve consideration, as this has a significant influence on the following stages of the project (Rosso et al., 2014). It is necessary to involve all IGs in defining elements of the project scope to ensure their successful involvement and improve the project results (Bourne \& Walker, 2008). Appropriate and sufficient involvement and contributions of the IG can be considered a determining factor to achieve the desired project objectives and increase the chances that the IGs perceive the project as successful (Aaltonen et al., 2008).

Both, the criteria of successful projects and project management success, must satisfy the expectations of the IGs where their interests are connected with these criteria. For example, the $\mathrm{PMBOK}^{\circledR}$ (PMI, 2017) connects the satisfaction of the IG with the success of the project: "the project management team should identify the stakeholders, determine what their needs and expectations are, and then manage and influence those expectations to ensure a successful project." The satisfaction of the IG is, therefore, a crucial criterion to achieve the success of the project. Similarly, Wideman (2004) states that the real measure of a project success lies in the satisfaction of the most relevant IG, the customer.

For obtaining the greatest benefit from IGs and achieving their satisfaction, they should be involved in an early stage of the project, so that their expectations about the project can be understood (Aaltonen et al., 2008; McElroy \& Mills, 2000; Olander, 2007; Walker et al., 2008). If we do not consider a diverse range of IG expectations, the project will not be seen as successful, in spite of whether the project manager is capable of executing the project within the original deadline, budget, and scope (Bourne \& Walker, 2005). Consequently, involving IG in the definition of the scope elements of the project that may affect them could increase their level of satisfaction, by giving them the opportunity to contribute and be heard in terms of their needs and requirements. With the contribution of all IGs, better-defined scope and effective project planning can be achieved, which also increases the likelihood of satisfactory results.

In recent years, sustainability has become the central axis of the development of the mining industry (see chapters 16 and 17 of the SME Mining Engineering Handbook (SME, 2012) and the first four chapters of Responsible Mining: case studies on the management of social and environmental risks in the developed world (SME, 2015)), where compliance with environmental regulations and relations with close communities for the development of mining projects have been preponderant factors. In line with this, this study takes into account and focuses its attention on mining projects of smaller magnitude, mainly executed for the improvement of the existing productive infrastructure. The novelty of the proposal is that most stakeholders are integrated to define the scope, covering key actors starting from the end user, to the executive and middle managers related to this type of projects. 
In summary, according to the theory of satisfaction-need and the theory of stakeholders, all individuals have different needs, desires and requirements, which determine their motivations in a particular situation or event. When these needs, wants and requirements are met, high levels of satisfaction occur (Galster \& Hesser, 1981). This can be evidenced in the context of the present study by stating that the satisfaction of an IG of a project increases when all IGs have the opportunity to define elements of scope related to their needs, desires, and requirements. Additionally, they will judge these elements once completed in relation to their expected results. The level of project satisfaction will increase as the needs, desires and requirements of the IG are reflected in the results of the project. Therefore, looking for a better way to manage the involvement of the IG in projects can generate significant benefits in terms of increasing the level of IG's satisfaction hence improving the project performance.

Methodology

The empirical development of this study is framed within the case method (Yin, 2009) by three main reasons: a large part of the research questions is of the "how" type (see Table 1); the treated material is novel and pertinent to the mining industry; and, the researcher has no control over the element to be investigated. Following the case study model proposed by Yin (2009), the present empirical research is carried out applying the inductive case method, since the hypotheses and the propositions generated from the theory of satisfaction-need and stakeholder's theory. Also, this study is classified as a single case of the coupled type, with different units of analysis: area managers, project managers, supervisors, and operators.

The case method is defined by five important components of the research design (Yin, 2009):

- The study questions.

- The theoretical propositions.

- The units of analysis, in this study, "selected IGs".

- The data related to the proposals.

- The criteria for interpreting the results of the investigation.

In this way, the research question to be answered is: how can the level of completeness of the project scope be improved, taking into account the participation of the IGs, in order to obtain better results in the mining projects? Additionally, from this proposed research question, the theoretical propositions, factors of analysis and corresponding units of analysis are defined and shows in details in Table 1.

Table 1. Theoretical propositions and factors of analysis. Source: Self-Elaboration.

\begin{tabular}{|c|c|c|}
\hline Theoretical propositions (TP) & Factors of analysis (FA) & Units of Analysis (UA) \\
\hline $\begin{array}{l}\text { TP1: A project will be better } \\
\text { defined in terms of scope when } \\
\text { the stakeholders' requirements } \\
\text { are correctly identified. }\end{array}$ & $\begin{array}{l}\text { FA1: How stakeholders are } \\
\text { managed. } \\
\text { FA2: How to identify the scope } \\
\text { requirements of the }\end{array}$ & \multirow{4}{*}{$\begin{array}{l}\text { Area Managers (2): They are in charge of } \\
\text { the strategic decisions related to the } \\
\text { project's development, and who receive } \\
\text { the initial requirements. } \\
\text { Project Managers (5): They develop and } \\
\text { prepare the projects in coordination with } \\
\text { the main organization, in their role as } \\
\text { Client and End User. } \\
\text { Supervisors ( } 2 \text { ): Each area of the main } \\
\text { organization has supervisors by specialty, } \\
\text { who directs the staff to guide and } \\
\text { supervise the performance of their duties. } \\
\text { Operators (2): are the end users (both to } \\
\text { operate and / or maintain it) of each } \\
\text { project undertaken by the main } \\
\text { organization. }\end{array}$} \\
\hline $\begin{array}{l}\text { TP2: Knowing the satisfaction level } \\
\text { of the interest groups regarding } \\
\text { the scope of a project in the early }\end{array}$ & $\begin{array}{l}\text { stakeholders. } \\
\text { FA3: How to establish } \\
\text { indicators of post-evaluation of } \\
\text { the project. }\end{array}$ & \\
\hline stages. & $\begin{array}{l}\text { FA4: How to define a metric of } \\
\text { satisfaction measurement. }\end{array}$ & \\
\hline $\begin{array}{l}\text { TP3: Knowing the participation level of } \\
\text { project stakeholders regarding the } \\
\text { scope is essential for the success of the } \\
\text { project. }\end{array}$ & $\begin{array}{l}\text { FA5: How to identify key } \\
\text { stakeholders in the scope } \\
\text { definition. } \\
\text { FA6: How to define the level of } \\
\text { stakeholder participation in the } \\
\text { scope definition in the early } \\
\text { stages. }\end{array}$ & \\
\hline
\end{tabular}

The preparation, collection, and analysis of the evidence are synthesized, the findings are adapted during the application of the empirical study, and the proposed premises are related, which has become the modifications of the proposed factors if it is necessary. 
Regarding the aim of the study, given the great variety of types of possible projects to be investigated (less than US\$ 15 millions); it is decided to delimit the sample to the so-called minor mining projects in Chile. This facilitates the application of the proposed method and the administration of associated results. The information is collected through surveys, interviews, and analysis of the assets of an organization in the Chilean copper mining industry, applied directly to everyone involved, in the areas that have the greatest impact on the management of the minor mining projects. The study also covers the direct user area of the executed projects.

In total, 11 interviews were carried out, corresponding to the areas involved from area directors to user operators. The interviews were conducted directly by the researchers through a questionnaire applied face-to-face in a specific meeting with each interviewee. Hence, the collected data include open comments and interesting details about the scope definition stage and the participation of key stakeholders in it.

The techniques used to analyze the evidence in this investigation correspond to the development of an explanation and the synthesis through crossed analysis of the evidence from each unit of analysis. Finally, the discussion of results and conclusions about each factor is delivered.

\section{Results and the proposed method for minor mining projects}

The following results are based on the data gathered. Six analysis factors were studied (see Table 1), which are presented step by step in the next sections.

\section{Results by factors of analysis}

Figure 1 shows that $92 \%$ of the respondents agree that it is necessary to manage the IGs in the projects. Addressing the concerns, interests, and expectations of the project's IGs can favor a better definition of the project scope. As mentioned above, the totality of the interviewees indicate that in project management the development and management of IG are low to very low throughout the project lifecycle and that there is no clear and feasible plan to interact with those interested in the project in order to balance their expectations with the project objectives and scope. From Figure 2, although the respondents recognize the contribution of the internal document of the company for the development of each element of the project scope, $83 \%$ of the interviewees indicate that their contribution to the scope definition in the pre-investment stage is low, and $92 \%$ mention that it is manifested in the investment stage at a high level. In summary, the contribution of the mentioned document is recognized to define the project scope. Nevertheless, the scope requirements in the pre-investment stage are not carried out with the participation of the key IGs.

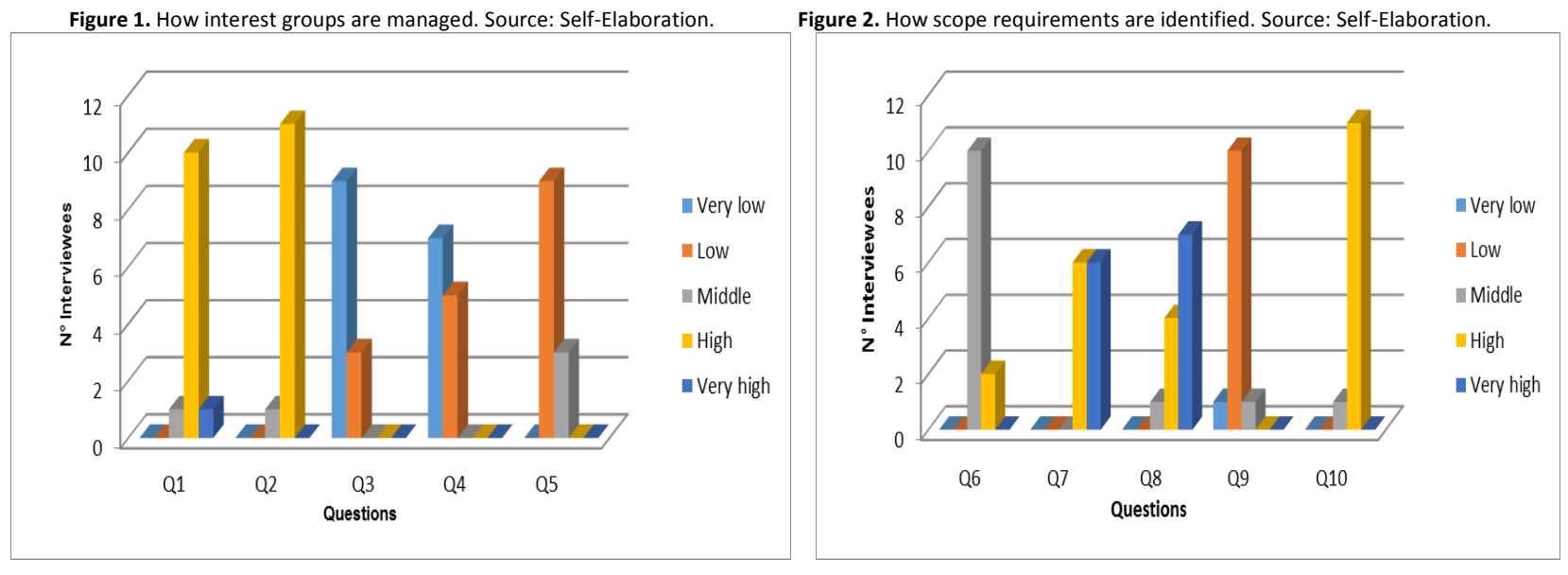

Figure 3 demonstrates that $100 \%$ of the interviewees agree that current indicators of the subsequent evaluation of the projects allow collecting real feedback from the IG from a low to a very low level. Also, $67 \%$ of the interviewees express that the indicators of the evaluation after the acceptance of the project results only have KPI of the projects in technical terms, the degree of satisfaction and fulfillment of the IG expectations. The measurement is made to the direct client area, which is not necessarily the only area that is influenced by the results of the project. A possible extension of the evaluation criteria after the project completion could provide valuable feedback from the IGs to the reach of the scope.

From Figure 4, $67 \%$ of the interviewees converge on the low level of acceptance/ satisfaction that the user areas and/or those interested in the projects have at the end of the investment stage. Also, almost $60 \%$ of respondents consider that the degree of fulfillment of IG expectations with respect to the final results of the projects is low, and only $42 \%$ consider 
them fulfilled to an average degree. More than $80 \%$ of practitioners in this survey consider that the degree of satisfaction that is perceived in the IGs may be influenced in large part by their participation (i.e., stakeholders) in defining the scope of the projects. Moreover, all interviewees are aware that, at the end of each project stage, there is no direct measure of the degree of satisfaction of the interested parties with respect to the scope of the project. Only a limited measurement of compliance with the KPIs of the projects is carried out. Considering the question if having a management tool for knowing the degree of stakeholders satisfaction with respect to the project scope would add value to the management of the projects, $83 \%$ of interviewees consider the contribution of this information to be high and, $17 \%$ mention that this contribution is very high. In general, there is a perception of low to medium degree of IG satisfaction with respect to the results of the revised projects.

On the other hand, Figure 5 shows results regarding specific queries: How often are IGs identified and classified in the project plans? $91.6 \%$ of respondents indicate that it is done with low frequency. All interviewees state that well-defined formal relationship of the IG with respect to the scope definition should be in the form of a signed agreement with the company or project.
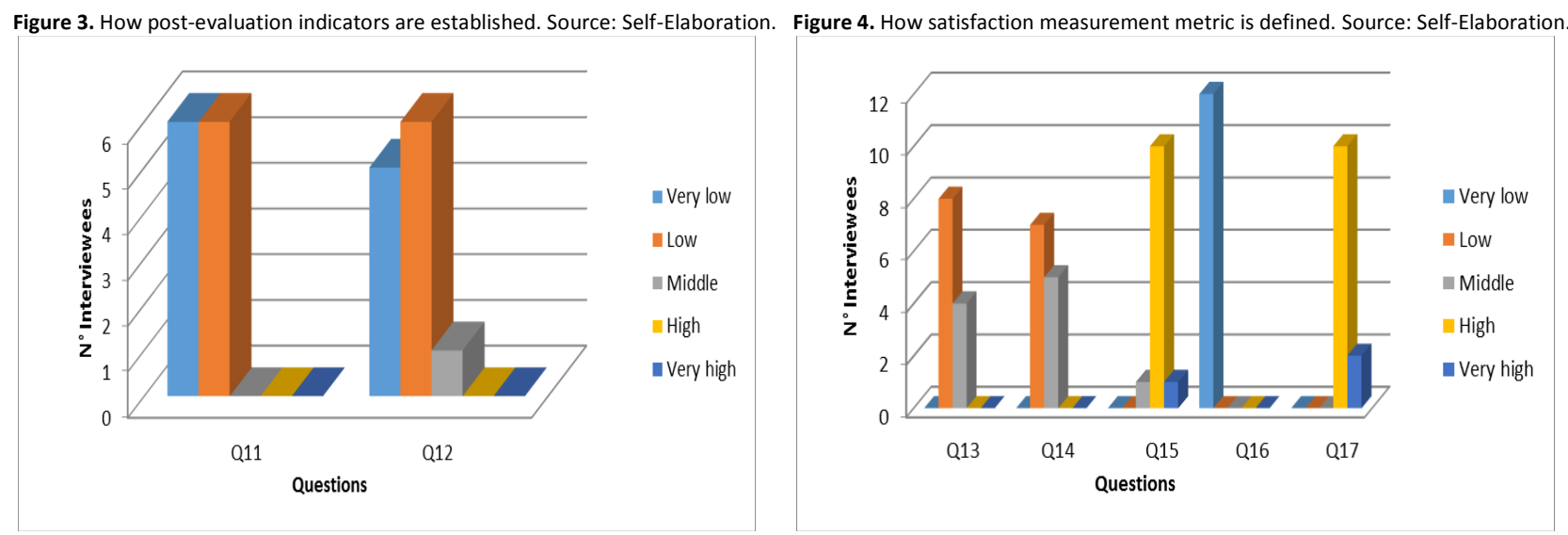

As presented in Figure 6, 100\% of the interviewees agree that it is fairly important or important that the IGs participate in the project definition phase. Although also all consider that it is relevant to the IGs participation and the generation of plans, that plans are not satisfactorily implemented due to lack of time. Regarding the project phase in which greater participation of the IG is evident, this manifests mainly in the investment phase of the project, while the participation in the pre-investment phase varies from low to very low. When consulted by the degree to which they consider that the project managers execute the defined plans to manage the IG in the projects, most of the project managers affirm that they intend to incorporate the IG. Also, the supervisors and operators accept the invitation to participate that is made; however, do not have the time to perform this management.
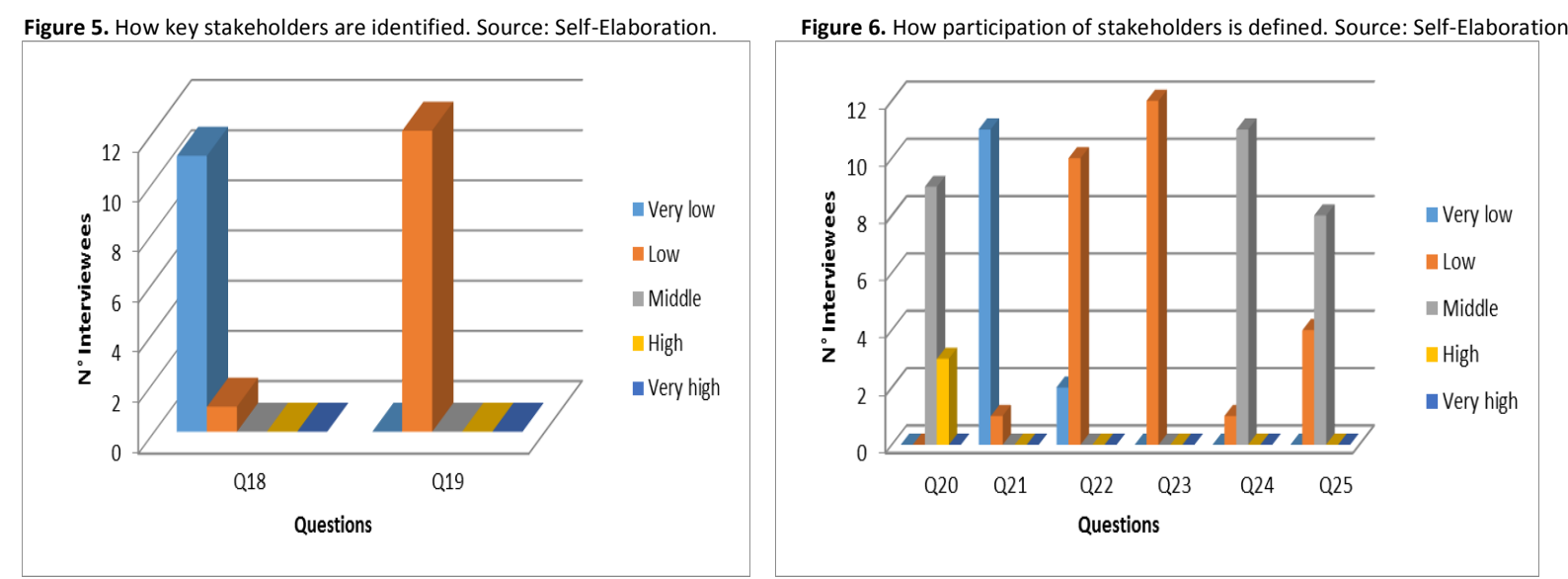

It is clear from the conversation with the interviewees that in general the key professionals in the definitions of the projects are faced with a high workload. Time of the professionals is too short of participating in meetings with extensive workshops, nor have they had practical tools that encourage their participation. 


\section{Unit of analysis 1: Area managers}

The need to manage the IG is recognized. They do not identify formal spaces in which they can express their satisfaction with the results of the projects, except through their direct leadership. They consider themselves to be contributors to the solution of problems. The area managers do not have clarity regarding how the scope of the projects is defined and, they do not know the internal manual.

The need to manage the IG is recognized. They perceived their participation in the projects as punctual and focused, concentrated mainly in the execution stage of the projects (investment).

A standardized and systematic procedure to define project scope can improve its results, in terms of its performance of the objectives proposed for it and greater satisfaction of the associated stakeholders.

\section{Unit of analysis 2: Project managers}

There is consistency with the unit of analysis 1 regarding the need to manage the IG. Currently, although there is a structure to identify and classify the IG, in practice it is done informally, treating all IGs in the same way. However, this unit of analysis emphasizes that the involvement must be controlled based on the quantification of the relative importance of each input, requirements, and concerns of each IG, but referred to each element of the scope defined in the internal manual of the company. It follows, then, that project managers validate the aforementioned manual as a reference for defining the scope of the projects.

The respondents in this group indicate that there are no practical tools that can serve as a guide on how to order the participation of the IG in the definition of the scope of the projects. It is agreed that the post-evaluation indicators do not allow for the level of satisfaction of the IGs to be collected, their structure is rigid and oriented towards meeting the project objectives.

\section{Unit of analysis 3: Supervisors}

The need to manage the IGs is recognized. Supervisors perceive their participation in the projects as punctual and focused, concentrated mainly in the execution stage of the projects (inversional phase). They do not have allowed defining the project scope; they only make sense to the internal procedures. Also, respondents in this group do not identify formal spaces in which they can express their satisfaction with the project results. Satisfaction regarding the results of the projects is made known through their direct leadership and/or when they are invited to participate in meetings or workshops.

It is clear from the interview that when their participation in the definition of the project scope has been greater, the level of satisfaction increases. Supervisors know the subsequent evaluation forms, but they make the reservation that the direct client area is not necessarily the only area that is influenced by the results of the project.

\section{Unit of analysis 4: Operators}

Similarly, to previous units of analysis, the need to manage the IG is recognized. Operators do not identify formal spaces in which they can express their satisfaction with the results of the projects, except through their direct leadership. Also, they consider themselves to be contributors to problems solutions. This group of respondents does not have clarity regarding how the project scope is defined and, they do not know the internal procedures. Finally, they perceive their participation in the projects as punctual and focused, concentrated mainly in the project execution stage (investment phase).

A standardized and systematic procedure to define project scope can improve results, in terms of its performance of the proposed objectives, and greater satisfaction of the associated stakeholders. 


\section{The proposed method for minor mining projects}

The deliverable of the present study is based on a case study developed in an engineering project executed between 2014 and 2016 within the work plan of the Engineering Projects Area of a large mining company in Chile.

\section{Development of the tool}

The tool developed to assess the degree of completeness of the project scope, considering the input and relative importance of the IGs associated with the project, was applied by the Project Manager at the end of the development of feasibility engineering. The associated results are presented below.

\section{a) Definition of project scope elements}

In accordance with the method proposed, the Project Manager, supported by the advice of his project team and special advisers, establishes the following elements of scope as critical to the project success (see Table 2 ):

\begin{tabular}{lll} 
& & Table 2. Scope elements. Source: Self-Elaboration. \\
\hline $\mathrm{N}^{\circ}$ & Categories & Elements \\
\hline 3 & Sustainability & 3.1 Environment report \\
& & 3.2 Plan for obtaining permits \\
5 & Project execution plan & 5.2 Planning and programming report \\
& & 5.3 Engineering report \\
& & 5.6 Commissioning report \\
& & 5.9 Risk management report \\
7 & Capital cost (CAPEX) & 7. Capital cost report \\
\hline
\end{tabular}

The reasons that justify this approach are as follows:

- The schedule responds to the main concern of the Project Manager. This is because there is a deadline by which the results of the project must be in operation.

- It is key to address environmental aspects and permits, because they impact on the general work program, depending on the time of preparation and corresponding processing.

- The project execution aspects are a concern of the Project Manager in relation to minimizing any planning failure that would impact on the time for developing the project investment stage.

- The costs are relevant for the Project Manager in response to the situation of a cost containment plan at the corporate level, which has meant reviewing the costs of the portfolio of projects throughout the area and finding savings opportunities without impacting the project objectives compliance.

\section{b) Definition of the significance of the project scope elements}

Next, the Project Manager, jointly with the advice of his/her project team and special advisors (by expert judgment), defines the following specific weight for each project scope element (see Table 3). For this, the criteria which were discussed and agreed upon in workshops are the specific scope, the project type involved and the stage of the project.

Table 3. Importance of scope elements. Source: Self-Elaboration.

\begin{tabular}{llll}
\multicolumn{3}{c}{ Table 3. Importance of scope elements. Source: Self-Elaboration. } \\
\hline $\mathrm{N}^{\circ}$ & Categories & Elements & Weight (\%) \\
\hline 3 & Sustainability & 3.1 Environment report & 10 \\
& & 3.2 Plan for obtaining permits & 20 \\
5 & Project execution plan & 5.2 Planning and programming report & 20 \\
& & 5.3 Engineering report & 20 \\
& 5.6 Commissioning report & 5 \\
& 5.9 Risk management report & 15 \\
7 & Capital cost (CAPEX) & 7. Capital cost report & 10 \\
& & 100 \\
\hline
\end{tabular}


Considering the project management literature and the critical IGs in the mining industry, the Project Manager determines that the opinions of the following IGs should be considered for defining the final extent of the project scope elements during the feasibility study. This is in order to ensure project success in its investment stage. Table 4 shows the identified IGs.

\begin{tabular}{|c|c|c|}
\hline Classification & Area & IG category \\
\hline Internal & Divisional management team & $\begin{array}{l}\text { General manager } \\
\text { Sustainability manager } \\
\text { Operations manager } \\
\text { Project manager - PMO officer }\end{array}$ \\
\hline Internal & Project management team (owner) & $\begin{array}{l}\text { Project manager } \\
\text { Engineering leader } \\
\text { Programming and control leader } \\
\text { Cost estimate leader }\end{array}$ \\
\hline External & $\begin{array}{l}\text { IG associated with the organization's } \\
\text { environment }\end{array}$ & $\begin{array}{l}\text { Engineering contractor } \\
\text { Communities / neighborhood board } \\
\text { Local, regional and national authorities }\end{array}$ \\
\hline
\end{tabular}

\section{d) Identification of the IG's interests and concerns}

Table 5 presents a matrix of the project which relates the scope elements and the IGs. That means the definition of each project scope element is aroused from each IG which is involved in this process. This identification promotes to improve the degree of satisfaction with the result of the project, by participating in the completeness of the elements of the respective scope.

\begin{tabular}{|c|c|c|c|c|c|c|c|c|c|c|c|c|c|}
\hline & & & \multicolumn{11}{|c|}{ Interest group (IG) } \\
\hline $\mathrm{N}^{\circ}$ & Categories & Elements & 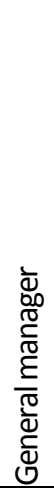 & 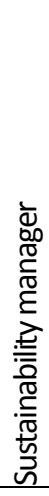 & 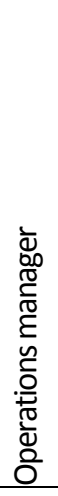 & 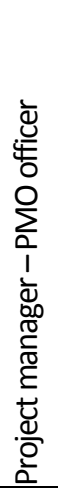 & 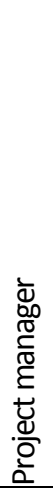 & 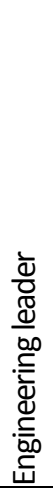 & 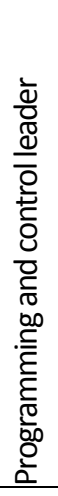 & 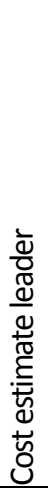 & 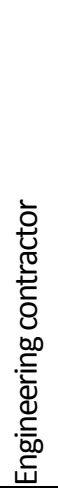 & 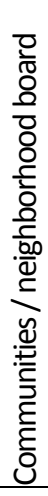 & 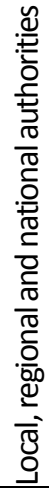 \\
\hline \multirow[t]{2}{*}{3} & Sustainability & 3.1 Environment report & $X$ & $X$ & & & $\mathrm{X}$ & & & & & $X$ & $x$ \\
\hline & & 3.2 Plan for obtaining permits & $X$ & $X$ & & & $x$ & & & & & $X$ & $X$ \\
\hline \multirow[t]{4}{*}{5} & Project execution & 5.2 Planning \& programming report & $X$ & $X$ & & $X$ & $\mathrm{X}$ & & $X$ & & & & \\
\hline & plan & 5.3 Engineering report & & & & & $X$ & $X$ & & & $X$ & & \\
\hline & & 5.6 Commissioning report & & & $x$ & & $\mathrm{X}$ & $x$ & & & $x$ & & \\
\hline & & 5.9 Risk management report & & $X$ & $X$ & $X$ & $\mathrm{X}$ & & & & & & \\
\hline 7 & $\begin{array}{l}\text { Capital } \\
\text { (CAPEX) }\end{array}$ & 7. Capital cost report & $X$ & & & $x$ & $\mathrm{X}$ & & & $X$ & & & \\
\hline
\end{tabular}

\section{e) Definition of the degree of importance by IG}

The results of the relative importance of each IG with respect to the scope element in which they have participated are presented (see Table 6). The Project Manager, through the technique of the application of expert judgment and with 
the support of his/her team and carrying out specialized workshops, is responsible for defining the specific weight of each IG that applies to the project in charge, expressed in percentage.

Table 6. The degree of importance by IG for each project scope element. Source: Self-Elaboration.

\begin{tabular}{|c|c|c|c|c|c|c|c|c|c|c|c|c|c|c|}
\hline \multirow[b]{2}{*}{$\mathrm{N}^{\circ}$} & \multirow[b]{2}{*}{ Categories } & \multirow[b]{2}{*}{ Elements } & \multicolumn{11}{|c|}{ Interest group (IG) } & \multirow[b]{2}{*}{ Total } \\
\hline & & & 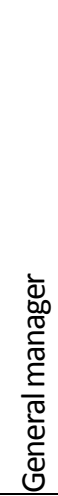 & 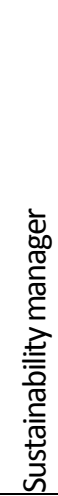 & 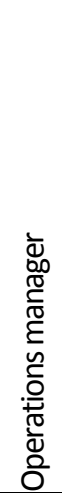 & 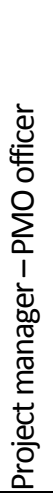 & 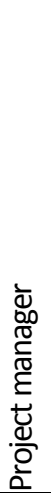 & 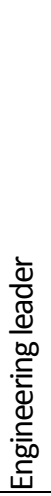 & 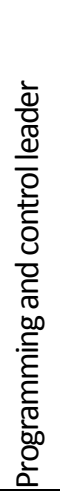 & 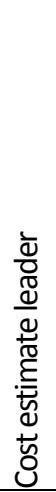 & 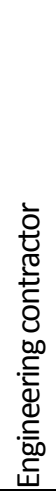 & 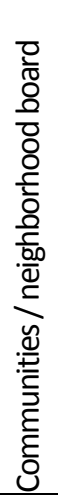 & 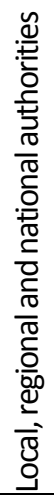 & \\
\hline \multirow[t]{2}{*}{3} & Sustainability & 3.1 Environment report & 25 & 50 & & & 5 & & & & & 10 & 10 & 100 \\
\hline & & 3.2 Plan for obtaining permits & 25 & 50 & & & 5 & & & & & 10 & 10 & 100 \\
\hline \multirow[t]{4}{*}{5} & $\begin{array}{l}\text { Project execution } \\
\text { plan }\end{array}$ & $\begin{array}{l}5.2 \text { Planning \& programming } \\
\text { report }\end{array}$ & 20 & 30 & & 20 & 20 & & 10 & & & & & 100 \\
\hline & & 5.3 Engineering report & & & & & 20 & 30 & & & 50 & & & 100 \\
\hline & & 5.6 Commissioning report & & & 30 & & 40 & 20 & & & 10 & & & 100 \\
\hline & & 5.9 Risk management report & & 40 & 10 & 20 & 30 & & & & & & & 100 \\
\hline 7 & $\begin{array}{l}\text { Capital } \\
\text { (CAPEX) }\end{array}$ & 7. Capital cost report & 30 & & & 20 & 30 & & & 20 & & & & 100 \\
\hline
\end{tabular}

\section{f) Procedure}

First, multiply the importance of the scope element (Table 3) by the contribution/specific weight of each associated IG in defining the element (Table 6).

Second, divide the result of the previous step by 100 to keep the sum of the contributions of the IG equal to the importance / specific weight of the scope element. See the results in Table 7.

Each number shown in Table 7 represents the relative importance of an IG in defining and evaluating the associated scope element. In those cells where there are no numbers, the corresponding IG does not need to participate in the definition and evaluation of that specific scope. High weights reflect greater importance with respect to the input of the IG for completeness of the project scope elements.

Third, once the feasibility study advances to the stage of presenting the results for the owner's review, the next step is to request each IG involved in evaluating the degree of satisfaction with the complete definition of the respective scope, and to what extent the definition matches their requirements in the project. Thus, participants are asked to use a Likert scale of satisfaction level from very satisfied (100\%), satisfied (75\%), partially satisfied (50\%), unsatisfied (25\%) and very dissatisfied (0\%), where each point indicates the opinion of the respondent / IG regarding the completeness of project scope definition. Figure 7 exhibits the applied Likert scale (Likert, 1932). 

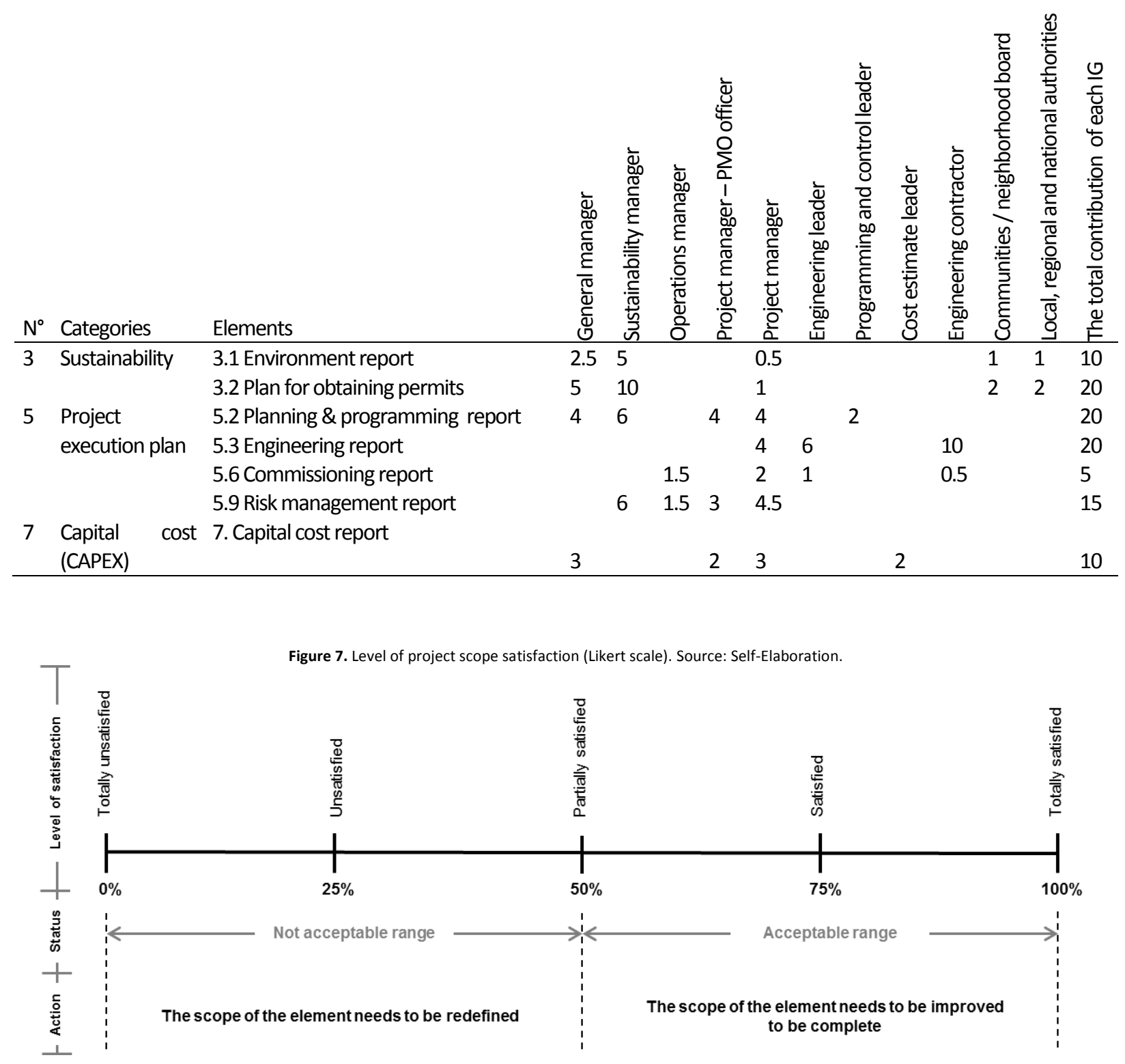

According to Figure 7, values under $50 \%$ of satisfaction with respect to the degree of completeness of the evaluated scope element imply that it is not acceptable and that the element must be redefined. In addition, low values indicate an extension of the scope and increase in the uncertainty and probability of risks during the project implementation phase, if the decision makers accept it.

The respondents indicate the degree of satisfaction with the completeness of the definition of each project scope element, during the process of presenting the preliminary results of feasibility engineering. In the case of the IG communities and authorities, only one organization by entity is surveyed. The evaluation of the degree of satisfaction is made on the basis of formal presentations of the results of the specific studies according to the respective scope element and summarizing the feedback of each associated IG. The results obtained are presented in Table 8 below.

As shown in Table 8, none of the critical elements for the success of the project fails to reach the minimum level of satisfaction or acceptance from the associated IGs (all scores over 50\%). The main reason that explains the previous results is in the early identification of the IG that should be considered. According to each project scope element, the concerns and requirements of each IG are included as an input for the development of the feasibility engineering study. 
This situation is expressed once the study was completed and the preliminary results are obtained and presented. Additionally, in this process of understanding the concerns and requirements of each IG, the project manager's expert judgment is the key for identifying, analyzing and evaluating who should participate, and how each input should be incorporated throughout the development of engineering. The project manager supports his/her decisions on the basis of requesting expert opinions from the project team and special advisors, including the organization knowledge and the social and environmental context in which the organization operates.

Table 8. The degree of IG satisfaction related to project scope elements. Source: Self-Elaboration. Interest group (IG)

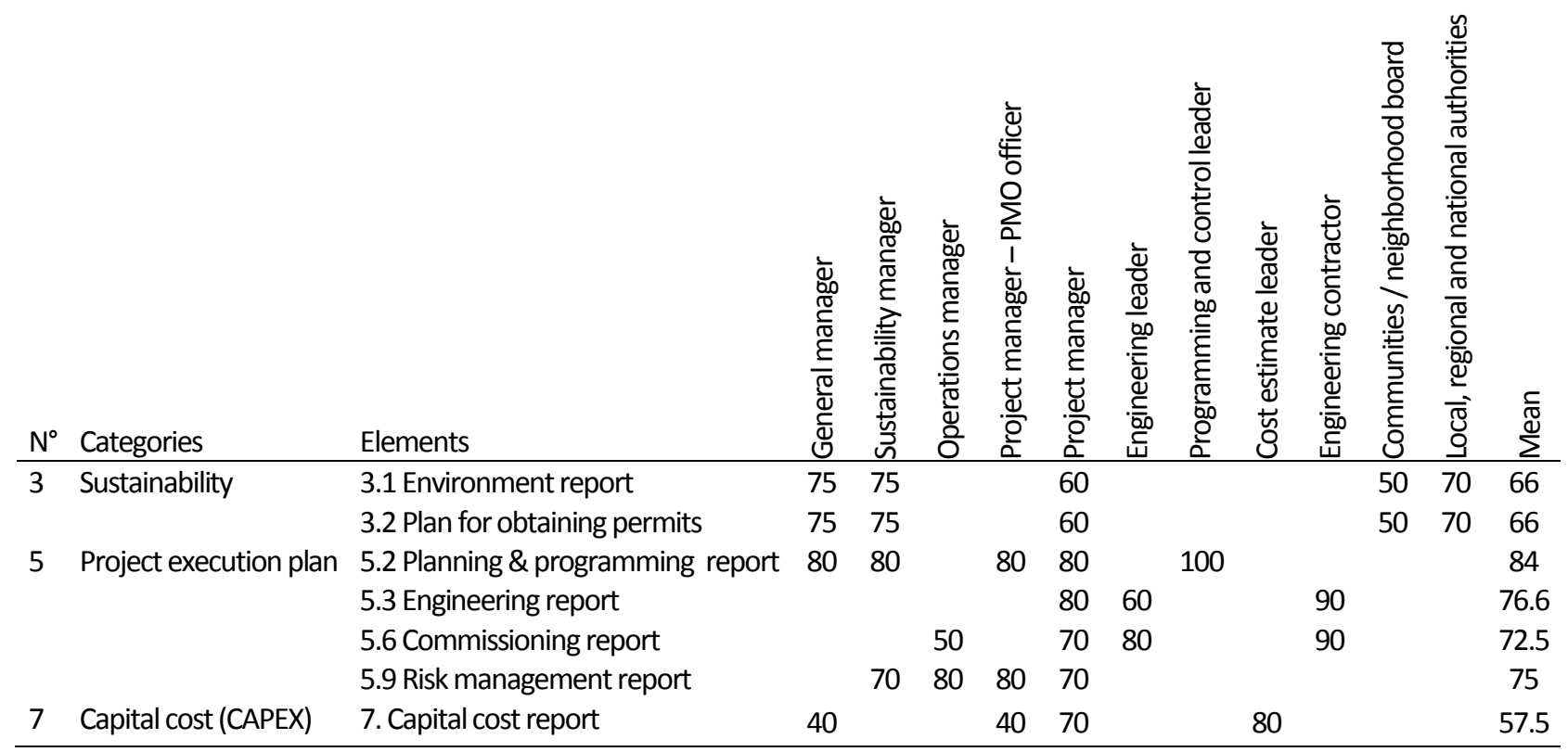

Fourth, the relative importance of each IG in relation to the degree of satisfaction achieved is considered below. Each level of satisfaction, according to the scope element, is multiplied by the specific weight of importance of each IG obtained (see Table 7), and then divided by 100. The level of completeness of each scope element of the project is the sum of the evaluation scores for all the IGs involved. The final score of the completeness of the scope definition package, considering all the IG involved in the evaluation process, is the sum of all the levels of completeness of all the elements of scope definition of the project. These values are presented in Table 9. As a result, the average score of the completeness of the definition of project scope packages, when all the IGs have participated based on the importance of its input is $71.6 \%$.

On the other hand, if the results of Table 8 are compared with those of Table 9, after converting the evaluation scores of each IG in each scope definition element, there are small variations (increase and decrease) in the degree of satisfaction of completeness of each project scope element. These variations are due to the relative importance of the specific weight of each IG with respect to the associated element. This determines the influence of opinion of certain IGs in relation to each other. Also, certain input dominates others in accordance with the relative importance assigned, and each associated scope element. Therefore, the evaluation of the completeness of the project scope is affected.

Table 10 compares the results obtained by assuming equal values (Table 8) and variable values (Table 9) regarding the importance of each IG in accordance to the degree of satisfaction for each project scope element. 


\begin{tabular}{|c|c|c|c|c|c|c|c|c|c|c|c|c|c|c|c|}
\hline $\mathrm{N}^{\circ}$ & Categories & Elements & 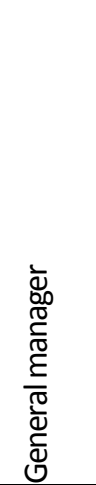 & 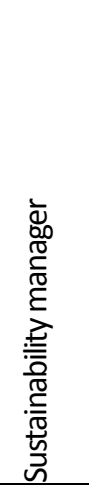 & 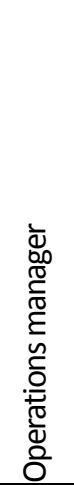 & 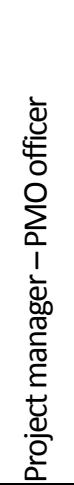 & 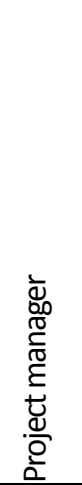 & 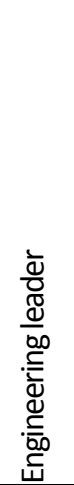 & 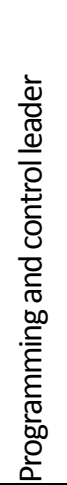 & 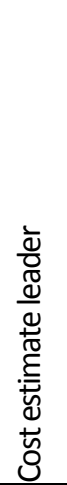 & 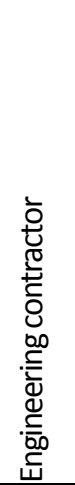 & 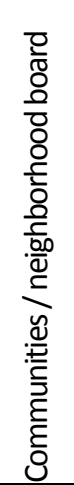 & 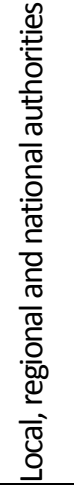 & 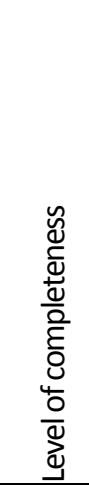 & 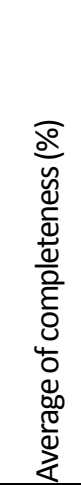 \\
\hline \multirow[t]{2}{*}{3} & Sustainability & 3.1 Environment report & 1.875 & 3.75 & & & 0.3 & & & & & 0.5 & 0.7 & 7.125 & 71.3 \\
\hline & & $\begin{array}{l}\text { 3.2 Plan for obtaining } \\
\text { permits }\end{array}$ & 3.75 & 7.5 & & & 0.6 & & & & & 1 & 1.4 & 14.25 & 71.3 \\
\hline \multirow[t]{4}{*}{5} & $\begin{array}{l}\text { Project execution } \\
\text { plan }\end{array}$ & $\begin{array}{l}5.2 \text { Planning \& } \\
\text { programming report }\end{array}$ & 3.2 & 4.8 & & 3.2 & 3.2 & & 2 & & & & & 16.4 & \\
\hline & & 5.3 Engineering report & & & & & 3.2 & 3.6 & & & 9 & & & 15.8 & 79 \\
\hline & & 5.6 Commissioning report & & & 0.75 & & 1.4 & 0.8 & & & 0.45 & & & 3.4 & 68 \\
\hline & & $\begin{array}{l}5.9 \text { Risk management } \\
\text { report }\end{array}$ & & 4.2 & 1.2 & 2.4 & 3.15 & & & & & & & 10.95 & 73 \\
\hline 7 & $\begin{array}{l}\text { Capital } \\
\text { (CAPEX) }\end{array}$ & 7. Capital cost report & 1.2 & & & 0.8 & 2.1 & & & 1.6 & & & & 5.7 & 57 \\
\hline
\end{tabular}

Table 10. Comparison level of satisfaction according to relative IG importance. Source: Self-Elaboration.

\begin{tabular}{|c|c|c|c|c|c|}
\hline $\mathrm{N}^{\circ}$ & Categories & Elements & $\begin{array}{l}\text { Level of satisfaction without } \\
\text { difference of IG importance } \\
(\%)\end{array}$ & $\begin{array}{l}\text { Level of satisfaction with a } \\
\text { difference of IG importance } \\
(\%)\end{array}$ & Variation \\
\hline \multirow[t]{2}{*}{3} & Sustainability & $\begin{array}{l}\text { 3.1 Environment } \\
\text { report }\end{array}$ & 66 & 71.25 & Increase \\
\hline & & $\begin{array}{l}3.2 \text { Plan for obtaining } \\
\text { permits }\end{array}$ & 66 & 71.25 & Increase \\
\hline \multirow[t]{4}{*}{5} & $\begin{array}{l}\text { Project } \\
\text { execution plan }\end{array}$ & $\begin{array}{l}5.2 \text { Planning and } \\
\text { programming report }\end{array}$ & 84 & 82 & Decrease \\
\hline & & 5.3 Engineering report & 76.6 & 79 & Increase \\
\hline & & $\begin{array}{l}5.6 \text { Commissioning } \\
\text { report }\end{array}$ & 72.5 & 68 & Decrease \\
\hline & & $\begin{array}{l}5.9 \text { Risk management } \\
\text { report }\end{array}$ & 75 & 73 & Decrease \\
\hline 7 & $\begin{array}{l}\text { Capital cost } \\
\text { (CAPEX) }\end{array}$ & 7. Capital cost report & 57.5 & 57 & Decrease \\
\hline
\end{tabular}

In this case study, although changes are observed, these do not affect the overall satisfaction scores on the completeness of the project scope. In other words, there is not a need to rethink-adjust-update-improve the feasibility study. According to the results obtained from the application of this tool developed, it can be inferred that the feasibility study developed takes and responds satisfactorily to the requirements and concerns of each relevant IG. This can allow inferring that the project in its investment stage will be executed according to the plan, achieving the project objectives and satisfying the interests of the involved stakeholders. Moreover, this procedure contributes to meet the deadlines given by the regulations that apply to the company and strengthening the social license of operation of the area. 
The aim of this study is to address the issue about the stakeholders' involvement in mining projects, and then to develop an assessment procedure that delivers results for the benefit of the organization and meets the expectations of all interested parties. Also, this methodology is proposed for helping the project management team to identify and prioritize the involvement of each associated IG systematically.

The suggested methodology facilitates answering the key questions of this study, summarizing the conclusions as follows:

1. The research defines 21 critical project scope elements that should be considered in the development of minor projects with an emphasis on the pre-investment stage.

2. Categories of internal and external IG are determined which should ideally be involved in the process of preparing the project scope definition document referring to projects in a mining company. The relative importance value of each stakeholder must be determined case by case according to the specific characteristics of each project, based on the internal and external reality in which the project is immersed.

3. A management tool is developed to measure the level of completeness of project scope definition based on the stakeholders' inputs. This is achieved by integrating the specific importance of each element with respect to the completeness of the project scope definition with the importance of each stakeholder's input that contributes to the completeness of each element. This proposed procedure allows measuring in a relative manner the final degree of satisfaction of all the stakeholders involved regarding the completeness of the project scope achieved.

4. This procedure represents a proposal to respond to the need for developing managerial instruments that allow IG systematically to be involved in investment projects in the mining industry, according to their degree of importance.

5. The applied methodology is a case study which includes a survey, interviews and background information from a mining organization. The study achieves the important participation of critical stakeholders involved in a minor mining project, and it is presented as a representative case.

Despite following a comprehensive work method, the findings and conclusions reached in this study should be interpreted in light of several limitations identified during the realization of the study. First, the proposed procedure is conducted within the context of the projects in a specific organization; therefore, the scope elements and the associated interest groups are only applicable in this context. However, this study can be scaled for larger mining projects, and replicated for other industries such as construction and energy. Second, the focus of the study responds to a business unit level. That is, it does not include all the scope elements of a mining project or the associated interest groups at the level of a mining company, or the mining industry in Chile, or globally. Third, the proposed methodology was applied to a single case study. In order to validate the results obtained and improve the procedural and analysis aspects involved, it is necessary that the methodology developed to be tested in other projects. The fourth limitation is that the importance of the contribution of the IGs to the completeness of the project scope definition does not consider whether the IGs can influence other IGs to alter their behavior in relation to any activity (cross-influence). Consequently, new research can point to the analysis of the influence of different stakeholders according to their position with respect to the network of all the IGs of a project.

Finally, this research is based, mainly, on finding a practical solution to a real problem in the mining industry, relying on theories and recognized strategic management and project management approaches. Thus, the main contribution is to the adaptation of a validated scope-definition procedure to the analysis of minor mining projects, thus establishing a dynamic instrument that can be adapted and refined according to the type of project being addressed.

Aaltonen, K., Jaakko, K., \& Tuomas, O. (2008). Stakeholder salience in global projects. International Journal of Project Management, $26(5), 509-516$. Atkinson, H. (2006). Strategy implementation: a role for the balanced scorecard? Management Decision, 44(10), 1441-1460.

Bourne, L., \& Walker, D. (2005). Visualising and mapping stakeholder influence. Management Decision, 43(5), 649-660.

Bourne, L., \& Walker, D. (2008). Project relationship management and the Stakeholder Circle ${ }^{\mathrm{TM}}$. International Journal of Managing Projects in Business, $1(1), 125-130$.

Bryson, J. (2004). What to do when stakeholders matter: stakeholder identification and analysis techniques. Public Management Review, 6(1), 21-53. 
Chinyio, E. \& Akintoye, A. (2008). Practical approaches for engaging stakeholders: findings from the UK. Construction Management and Economics, 26(6), 591-599.

Dawis, R. (1994). The theory of work adjustment as convergent theory. In M. L. Savikas \& R. W. Lent (Eds.), Convergence in career development theories: Implications for science and practice (pp. 33-43). Palo Alto, CA, US: CPP Books.

Freeman, R. (2010). Strategic management: A stakeholder approach: Cambridge University Press.

Gallego-Ayala, J., \& Juízo, D. (2014). Integrating stakeholders' preferences into water resources management planning in the Incomati river basin. Water Resources Management, 28(2), 527-540.

Galster, G., \& Hesser, G. (1981). Residential satisfaction: Compositional and contextual correlates. Environment and Behavior, 13(6), 735-758.

Johnson, G., \& Scholes, K. (1999). Exploring corporate strategy. London, UK: Prentice-Hall.

Likert, R. (1932). A technique for the measurement of attitudes. Archives of Psychology, 22(140), 1-55.

Maslow, A. (1943). A theory of human motivation. Psychological Review, 50(4), 370.

McElroy, B., \& Mills, C. (2000). Managing stakeholders. Gower Handbook of Project Management, 757-775.

Mitchell, R., Agle, B., \& Wood, D. (1997). Toward a theory of stakeholder identification and salience: Defining the principle of who and what really counts. Academy of Management Review, 22(4), 853-886.

Mostafa, M., \& El-Gohary, N. (2014). Semantic system for stakeholder-conscious infrastructure project planning and design. Journal of Construction Engineering and Management, 141(2), 04014075.

Olander, S. (2007). Stakeholder impact analysis in construction project management. Construction Management and Economics, $25(3), 277-287$.

Phillips, R. (2003). Stakeholder legitimacy. Business ethics quarterly, 13(1), 25-41.

PMI. (2017). A Guide to the Project Management Body of Knowledge (PMBOK ${ }^{\circledR}$ Guide) (Sixth ed.). USA: Project Management Institute, Inc.

Rosso, M., Bottero, M., Pomarico, S., La Ferlita, S., \& Comino, E. (2014). Integrating multicriteria evaluation and stakeholders analysis for assessing hydropower projects. Energy Policy, 67, 870-881.

SME. (2012). SME Mining Engineering Handbook (3th Edition). S. G. Britton (Ed.). Denver: Society for Mining, Metallurgy, and Exploration.

SME. (2015). Responsible Mining: Case Studies in Managing Social \& Environmental Risks in the Developed World. S. G. Britton (Ed.). Denver: Society for Mining, Metallurgy, and Exploration.

Smith, A., \& Graetz, F. (2006). Organizing dualities and strategizing for change. Strategic Change, 15(5), $231-239$.

Walker, D., Bourne, L., \& Shelley, A. (2008). Influence, stakeholder mapping and visualization. Construction Management and Economics, 26(6), 645658.

Ward, S., \& Chapman, C. (2003). Transforming project risk management into project uncertainty management. International Journal of Project Management, 21(2), 97-105. doi:https://doi.org/10.1016/S0263-7863(01)00080-1

Wideman, R. (2004). A Management Framework: For Project, Program and Portfolio Integration: Trafford Publishing.

Yin, R. (2009). Case study research: Design and methods (applied social research methods). London and Singapore: Sage. 